\title{
HYDRATION OF PLASMA-TREATED ALUMOSILICATE BINDERS
}

\author{
Vít Šmilauer ${ }^{a, *}$, Oleg Babchenko ${ }^{b}, \check{S ̌ t e ̌ P A ́ N ~ P o t o c k Y ́ ~}^{b}$, \\ Alexander KromKa ${ }^{b}$
}

${ }^{a}$ CTU in Prague, Faculty of Civil Engineering, Department of Mechanics, Thákurova 7, 166 29, Czech Republic

${ }^{b}$ Institute of Physics of the ASCR, v.v.i., Cukrovarnická 10, Praha 6, 16253, Czech Republic

* corresponding author: vit.smilauer@fsv.cvut.cz

\begin{abstract}
Plasma treatment offers several applications in material science. In this research, the potential of plasma treatment is explored on the hydration of hydrophilic CNT-enriched cement and hydrophilic fly ash. The evolution of the hydration heat and the compressive strength show that a hydrophilic surface slightly accelerates the early-age hydration kinetics, while the long-term properties remain unchanged.
\end{abstract}

KEYWORDS: plasma treatment, CNT-enriched cement, hydrophilic fly ash, isothermal calorimetry, compressive strength.

\section{INTRODUCTION}

Alumosilicate binders, such as Portland cement blended with other mineral components, are the most man-made materials in the world. The world production of binders reached $3.6 \cdot 10^{9}$ tonnes in 2012, averaging about $500 \mathrm{~kg}$ per capita [1]. When dealing with such large amounts, any marginal improvement or cost-effective optimization brings substantial savings.

Plasma surface treatment is a well-established method for creating hydrophilic surfaces, which play an important role in hydraulic cementitious binders. This treatment was successfully used to improve the frictional bond between cementitious matrix and polyethylene fiber [2]. Plasma-treated carbon nanotubes grown directly on cement grains were proved to increase the compressive strength of cement paste slightly [3].

In concrete, the aggregate-cement matrix interface generally makes a weak mechanical bond. Plasma modification of the aggregate surface led to a slight improvement in the compressive strength, while the wettability of a steel substrate in contact with cement slurry showed significant changes after treatment [4].

Using fly ash as a partial substitute for cement has become a standard approach. Plasma treatment of fly ash to increase its hydrophilicity may act beneficially in blended cements, especially through the weak transition zone between an aggregate and a cementitious matrix. This type of scenario has not been studied in detail before and forms the main topic of this paper.

\section{MATERIALS}

Ordinary Portland cement CEM I 42.5 R from Mokrá, Czech Republic, $\left(\mathrm{OPC}_{\mathrm{H}}\right)$ was used as the source material for growing carbon nanotubes (CNTs) on the surface of its grains. Table 1 presents the oxide composition of the raw cement. Cement hybrid material

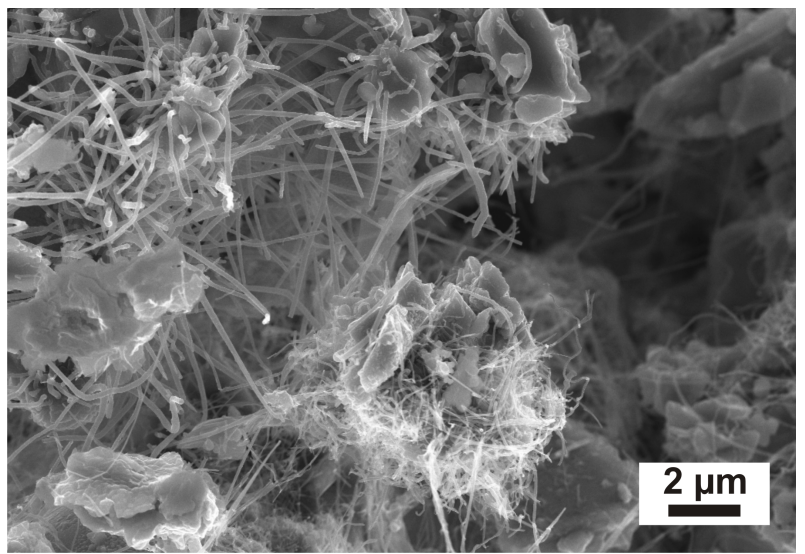

Figure 1. SEM image of the cement hybrid material with CNTs synthesized on its surface.

(CHM) with these grown CNTs on the surface was synthesized by a group from Aalto University, Finland, under the leadership of L. Nasibulina by the chemical vapor deposition method [5], Figure 1. CNT growth occurred at about $600{ }^{\circ} \mathrm{C}$ in a fluidized bed reactor, where acetylene served as the main carbon source due to its low decomposition temperature and its affordable price. The CNTs grown on the cement particles are approximately $30 \mathrm{~nm}$ in diameter and up to $3 \mu \mathrm{m}$ in length [6, and the specific surface area of the CNTs is about $10-20 \mathrm{~m}^{2} / \mathrm{g}$. Cement paste prepared with a CHM/water ratio of 0.407 and with no plasticizer served for testing the evolution of the hydration heat.

Ordinary Portland cement CEM I 42.5 R from Radotín, Czech Republic, (OPC) served as a reference binder for testing performance of fly ash. Fly ash of class F (FA), originating from the Opatovice brown-coal power plant, Czech Republic, was used as a blending material, Figure 2 Table 1 provides the oxide composition of both materials.

Table 2 summarizes the compositions of pastes and 


\begin{tabular}{llllllll}
\hline & $\mathrm{CaO}$ & $\mathrm{SiO}_{2}$ & $\mathrm{Al}_{2} \mathrm{O}_{3}$ & $\mathrm{Fe}_{2} \mathrm{O}_{3}$ & $\mathrm{Na}_{2} \mathrm{O}$ & $\mathrm{K}_{2} \mathrm{O}$ & $\mathrm{MgO}$ \\
\hline CEM I 42.5 R Mokrá $\left(\mathrm{OPC}_{\mathrm{H}}\right)$ & 63.77 & 20.51 & 4.74 & 3.30 & 0.15 & 0.95 & 1.05 \\
\hline CEM I 42.5 R Radotín $(\mathrm{OPC})$ & 65.65 & 19.75 & 4.35 & 2.63 & 0.09 & 0.080 & 1.80 \\
\hline Fly ash (FA) & 1.80 & 53.52 & 32.87 & 5.89 & 0.33 & 2.05 & 0.85 \\
\hline
\end{tabular}

TABLE 1. Oxide composition of Portland cement and fly ash.

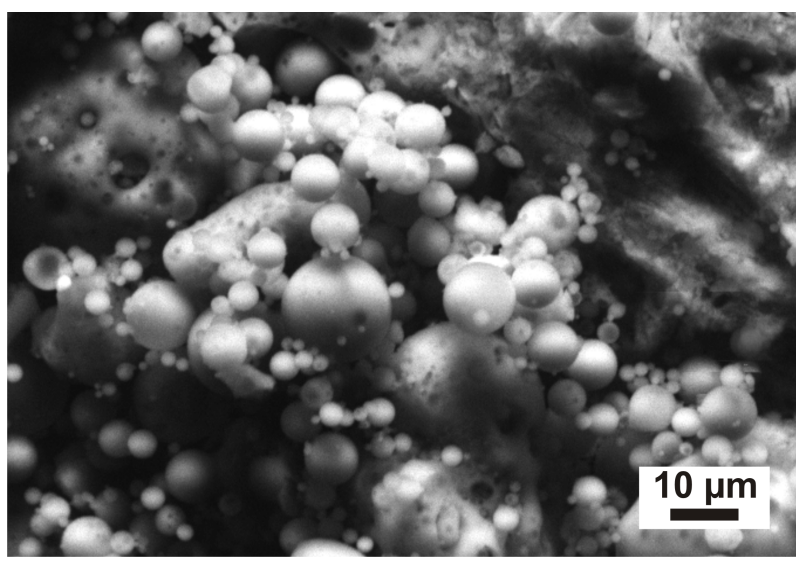

FIGURE 2. SEM image of the Opatovice fly ash.

mortar according to the EN 196 code. Overboiled tap water and a standard 0-4 mm sand from Zlosyň, Czech Republic, (S) were used. The level of FA replacement by mass was equal to $50 \%$ in the paste and $30 \%$ in the mortar. For the compressive strength test, $40 \times 40 \times 160 \mathrm{~mm}^{3}$ samples were cast, vibrated for 2 minutes and stored in a water bath at $22{ }^{\circ} \mathrm{C}$ prior to testing. For calorimetry, approximately $25 \mathrm{~g}$ of the mix was placed in a plastic ampoule and was then immediately placed inside an isothermal calorimeter. Samples for the mechanical tests were demoulded after 24 hours and stored under water until the mechanical tests were performed.

\section{Methods}

A large area AK 400 reactor (Roth\&Rau, MicroSystems) schematically shown in Figure 3, was used for surface modification by plasma treatment of CHM with grown CNTs and FA [7. As has been shown in earlier studies, 5 minutes of oxygen plasma treatment promotes the hydrophilic properties of as-grown carbon nanotubes, which were found useful for cell culturing application. It was also found that the long plasma treatment degrades the CNTs [8]. A similar procedure as in the latter work was therefore used for surface modification of CHM with CNTs.

Powder of CHM with previously synthesized CNTs was enclosed in Petri dishes and treated with radiofrequency (RF) activated oxygen plasma. The oxygen flow was set to $50 \mathrm{sccm}$ at a total gas pressure of $35 \mathrm{~Pa}$. The plasma discharge parameters were: RF power $50 \mathrm{~W}$ (area $600 \mathrm{~cm}^{2}$ ) and $-10 \mathrm{~V}$ substrate bias. This treatment lasted for $1 \mathrm{~min}$ at a temperature below

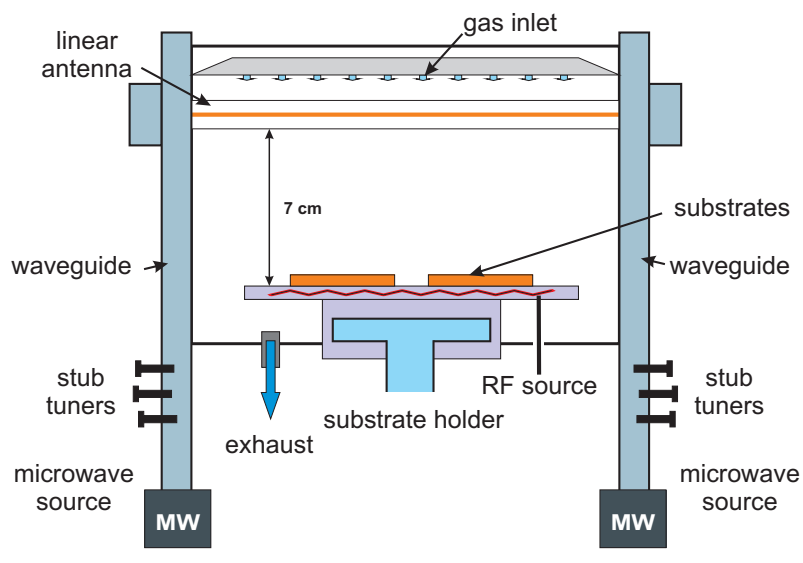

FiguRE 3. Schematic drawing of the pulsed linear antenna microwave plasma deposition system with $\mathrm{RF}$ substrate bias.

$50{ }^{\circ} \mathrm{C}$. In order to improve the functionalization homogeneity, the powder was mechanically mixed and the plasma treatment was repeated 5 times.

Inorganic FA can withstand harsher conditions during oxygen plasma treatment. The Petri dishes were filled with raw FA. Three different treatment regimes were tested, varying the plasma discharge power and treatment time:

FA1 - treatment at lower RF power for a longer time: $\mathrm{RF}$ power $50 \mathrm{~W},-10 \mathrm{~V}$ substrate bias, repeated 10 times.

FA2 - treatment at higher RF power for a shorter time: RF power $150 \mathrm{~W},-100 \mathrm{~V}$ substrate bias, repeated 5 times.

FA3 - treatment at higher RF power for a longer time: RF power $150 \mathrm{~W},-100 \mathrm{~V}$ substrate bias, repeated 10 times.

The oxygen flow in each case was $50 \mathrm{sccm}$, and the total gas pressure was $35 \mathrm{~Pa}$.

A TamAir isothermal calorimeter measured the heat flow under isothermal $20^{\circ} \mathrm{C}$. The heat flow was normalized per gram of OPC and integrated to the evolution of hydration heat.

\section{Results And Discussion}

The following section summarizes the experimental data from plasma-treated alumosilicate materials: paste made from CHM and paste/mortar with FA substitution.

The hydrophilic character is given by the top atomic layer oxygen bonded on the surface of the CHM and 


\begin{tabular}{lccccc}
\hline & CEM I 42.5 R (g) & Fly ash (g) & Sand (g) & Water (g) & Water/binder \\
\hline OPC (paste) & 300 & - & - & 150 & 0.50 \\
\hline OPC + FA (paste) & 150 & 150 & - & 150 & 0.50 \\
\hline S + OPC + FA (mortar) & 210 & 90 & 900 & 150 & 0.50 \\
\hline
\end{tabular}

TABLE 2. Compositions of pastes and mortar.

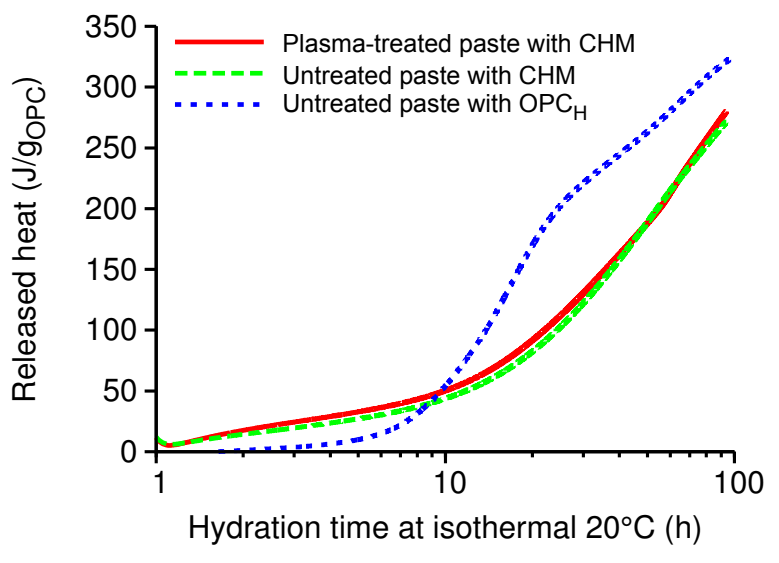

Figure 4. Hydration heat of plasma-treated CHM.

FA material by plasmatical processing. We focused on the influence of the hydration process itself, while further tailoring of modified interfaces in the cementitious matrices is also possible [2].

\subsection{Binder With PLASMa-treated CNT}

Plasma treatment seemed to be an appropriate method for increasing the uniform distribution of hydrophobic CNTs in a paste. After plasma treatment, the CHM became more hydrophilic, resulting in easier mixing with water. Figure 4 shows that plasma-treated CNTs yielded slightly faster early reaction kinetics. However, the CNTs on the surface of the cement grains hinder the acceleration period of cement hydration, as is evident if we compare the original $\mathrm{OPC}_{\mathrm{H}}$ with its CHM counterpart in Figure 4.

Our earlier paper demonstrated the effect of CHM on slightly improving the compressive strength and the fracture energy for pastes. Experiments and micromechanical simulations revealed that clustering of CNTs within the hydration products and their length up to $3 \mu \mathrm{m}$ are the major obstacles to an increase in strength due to the much larger fracture process zone 3 .

The changes in kinetics can be explained by the easier nucleation of the hydration products on a higher surface during initial hydration. Since hydration products block the access of water to a grain, the acceleration period is hindered.

\subsection{Plasma-treated Fly ash}

Plasma-treated FA3 and untreated FA in cement pastes behave identically during hydration of the paste

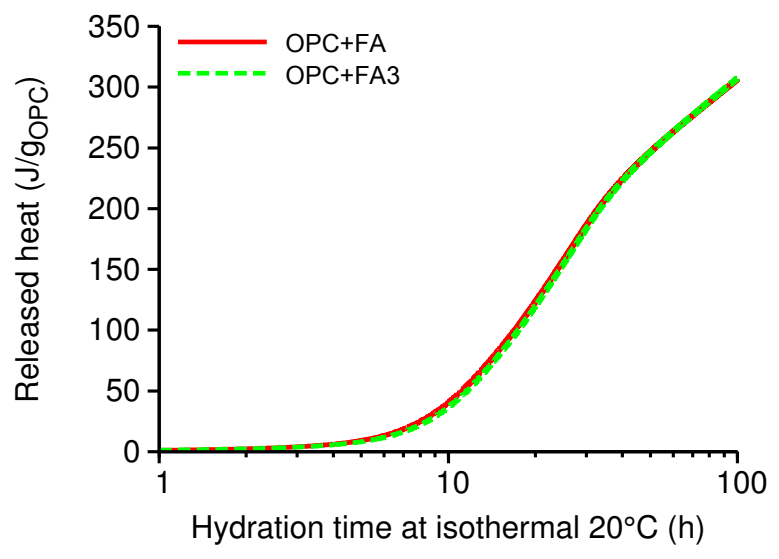

FiguRE 5. Hydration heat of FA and plasma-treated FA3 in cement pastes.

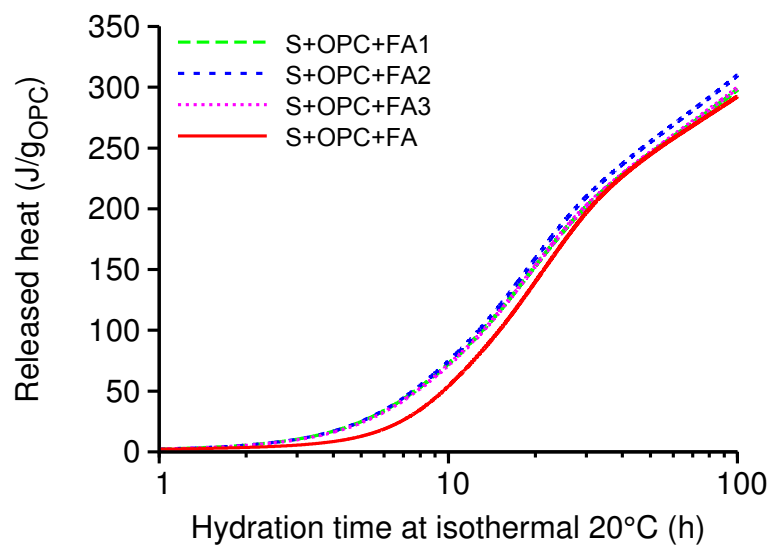

Figure 6. Hydration heat of raw FA and plasmatreated FAs in mortars.

as is shown in Figure 5 Both pastes have the identical surface area for early-age nucleation of hydration products. The water attraction on FA3 particles does not play any role in the blended system with such an excessive amount of water for hydration. The pozzolanic reaction between $\mathrm{Ca}(\mathrm{OH})_{2}$ and FA starts later, approximately after one week [9]. Due to the time limitation, Figure 5 shows data only for the first 100 hours.

The evolution of the released heat changes in a mortar system is depicted in Figure 6. Taking into account that there was no difference in the released heat in the pastes, the difference can be attributed only to the presence of sand particles. The most likely interpretation lies in the mix workability. 


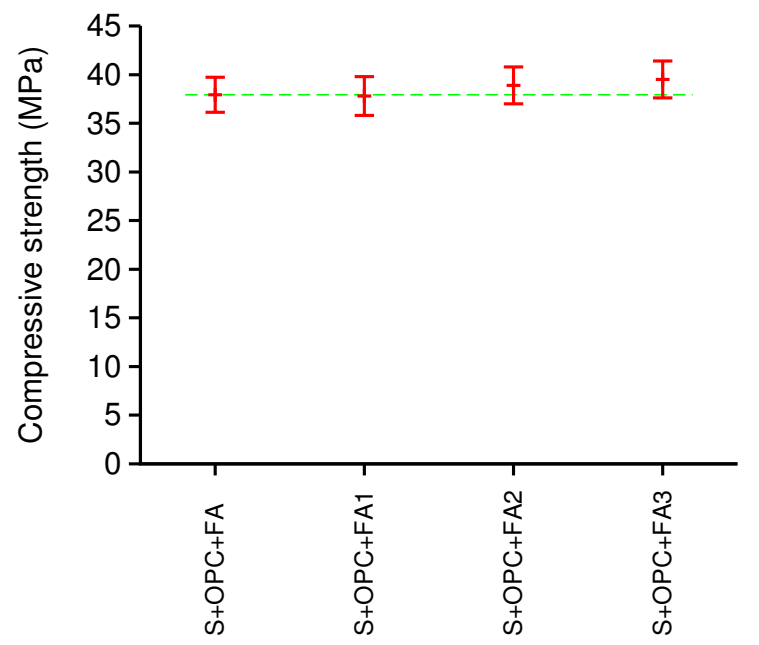

FiguRE 7. Compressive strength of the mortar with untreated and treated FA after 36 days with standard deviation.

Mixing intensity was previously found to have an effect on early-age hydration; proper and longer mixing led to an increase in heat flow during the first 30 hours [10. This time slot coincides well with the current data. The mixing protocol was kept constant for all samples. However, different workability results in different intensity of mixing, which is reflected by calorimetry. All plasma-treated FA1, FA2, FA3 exhibit similar behavior, meaning that even the lowest used power for plasma treatment increases the earlyage hydration kinetics, probably due to its influence on mixing.

Compressive strength tests, carried out 36 days after the casting, showed no significant change in the microstructure, see Figure 7. This result is consistent with the calorimetry data, since the same released heat corresponds to the same strength of the same cementitious binders. However, we can observe a systematic increase in the compressive strength of the mortar with increased RF power and time by $1.6 \mathrm{MPa}$ with respect to untreated FA. More tests are needed to confirm this trend.

\section{Conclusions}

A slight increase in early reaction kinetics was demonstrated for hydrophilic CNTs grown on the surface of cement grains. The acceleration phase of CHM hydration was delayed due to the formation of more hydration products during the early ages.

Hydrophilic fly ash slightly increased the early-age kinetics of cement hydration in mortars. Based on current data, the primary effect of hydrophilization was assigned probably to the mortar workability, which is secondarily manifested by intensified mixing and higher early-age kinetics. No significant effects of plasma treatment on the compressive strength of the mortar was found after 36 days of hydration. Early hydration quickly dissolves the hydrophilic layer, and the consequent hydration proceeds in a standard manner.

\section{ACKNOWLEDGEMENTS}

We would like to acknowledge the kind assistance of K. Hruška, Institute of Physics ASCR and L. Kopecký, CTU in Prague, for SEM images.

This work was financially supported by Czech Science Foundation research project $14-04790$ S and project SGS 14/121/OHK1/2T/11 of CTU in Prague. The work was carried out within the framework of the LNSM infrastructure at the Institute of Physics of the Academy of Sciences of the Czech Republic. The center for Nanotechnology in Civil Engineering served as a platform for collaborative work between the two institutions.

\section{REFERENCES}

[1] K. Coppenholle, et al. Key facts and figures. Tech. rep., The European Cement Association CEMBUREAU, Brussels, 2014.

[2] H.-C. Wu, V. C. Li. Fiber/cement interface tailoring with plasma treatment. Cement and Concrete Composites 21(3):205 - 212, 1999. DOI:10.1016/S0958-9465(98)00053-5

[3] V. Šmilauer, P. Hlaváček, P. Padevět. Micromechanical analysis of cement paste with carbon nanotubes. Acta Polytechnica 52:35-41, 1998.

[4] K. Shafiei, B. Hillemeier. Feasibility of plasma technology utilization in concrete industry. In V. Bílek, Z. Keršner (eds.), NTCC2014: Non-Traditional Cement Es Concrete V. Brno, 2014.

[5] L. I. Nasibulina, I. V. Anoshkin, S. D. Shandakov, et al. Direct synthesis of carbon nanofibers on cement particles. Transportation Research Record: Journal of the Transportation Research Board 2(2142):96 - 101, 2010. DOI:10.3141/2142-14

[6] P. R. Mudimela, L. I. Nasibulina, A. G. Nasibulin, et al. Synthesis of carbon nanotubes and nanofibers on silica and cement matrix materials. Journal of Nanomaterials 2009, 2009. DOI:10.1155/2009/526128

[7] Š. Potocký, M. Čada, O. Babchenko, et al. Perspectives of linear antenna microwave system for growth of various carbon nano-forms and its plasma study. Physica Status Solidi b 250(12):2723-2726, 2013. DOI:10.1002/pssb.201300085.

[8] M. Kalbáčová, A. Brož, A. Kromka, et al. Controlled oxygen plasma treatment of single-walled carbon nanotube films improves osteoblastic cells attachment and enhances their proliferation. Carbon 49(9):2926 2934, 2011. DOI:10.1016/j.carbon.2011.02.069

[9] L. Lam, Y. Wong, C. Poon. Degree of hydration and gel/space ratio of high-volume fly ash/cement systems. Cement and Concrete Research 30(5):747 - 756, 2000. DOI:10.1016/S0008-8846(00)00213-1

[10] L. Wadső. Using isothermal (heat conduction) calorimetry to study the effect of mixing intensity on reaction rate of cement mortars. In J. Beaudoin, J. Makar, L. Raki (eds.), 12th international congress on the chemistry of cement. Montreal, 2007. 